\title{
TRANSFORMING THE POST-SCHOOL SECTOR IN \\ SOUTH AFRICA: LIMITS OF A SKILLS-DRIVEN AGENDA
}

\author{
F. Maringe* \\ Leadership and Policy Studies \\ e-mail: felix.maringe@wits.ac.za
}

\section{R. Osman*}

Faculty of Humanities

e-mail: ruksana.osman@wits.ac.za

*University of the Witwatersrand

Johannesburg, South Africa

\section{ABSTRACT}

This theoretical and conceptual article explores the planned post-school sectoral reform in South Africa. The reform proposals set out in the White Paper (DoHET 2013) privilege a skills-based transformation agenda which we argue is inadequate to service the needs of a diverse postschooling sector in South Africa. In addition to a skills-driven discourse that is underpinning thinking about transforming the post-school sector, transformation as a construct has also not been fully engaged with in education policy. We thus also argue in this article that the good intentions that underpin the transformative process do not, on their own drive meaningful change in the sector. As a contribution to the development of a theoretically nuanced framing of transformation and as a prelude to articulating and implementing policy, the article proposes a force field of change defined by four pillars of transformation, which include the need to explore the impetus for change; capitalising on and developing the levers of change; reflecting on theoretical perspectives of educational transformation and understanding the mitigating barriers of transformation. We argue in this article that these aspects have received differentiated but broadly inadequate attention and that this may be partly responsible for the floundering nature of transformation in the post-school sector in South Africa.

Keywords: educational transformation, reform, South Africa, post-school sector, skills-driven transformation, information and knowledge

\section{INTRODUCTION AND SCENE SETTING}

Transforming South Africa's post-school system held out the promise of access and equity for students into a differentiated system which offered mobility and opportunities previously denied to the majority by apartheid. This transformation process has proven to be a Herculean task generating some success but also much disappointment in different sectors of society. 
Following Mbembe (2001), Mudimbe (2013) and Zeleza (2005), we take transformation to mean profound and radical change which makes for a clean break with the past and energises people towards new configurations, structures and processes. We argue in this article that despite the good intentions and the desire to transform South African post schooling system, we find ourselves traveling down the same blind alleys and reproducing the past in ways which amount to mere tinkering with change. Equally we argue that in South Africa, we have merely achieved reform and turn arounds and that real transformation has been elusive. Towards the end of this article, we provide a proposal for a framework that could help us achieve the transformation we need. Amongst the many reasons for this failure, we argue that the legacy of the apartheid system of education continues to rear its head in many respects, despite the substantial structural and ideological changes that have taken and continue to take place in our education systems. While access has been increased and democratised, and while the system now falls under unitary control and oversight, both systemic and institutional defects continue to characterise the transformative efforts (Samuel and Morrow 2004). For example, black students continue to perform poorly in terms of acquiring learning degree outcomes and in terms of retention while completion rates persistently remain low. In addition, while there has been a notable increase in the numbers of black staff in many institutions, the learning spaces in higher education (HE) for example continue to be dominated disproportionately by white faculty. We are thus with Mbembe (2001) who has argued elsewhere that the epistemological bases of what is taught in our institutions remain locked in a western discourse that stubbornly refuses to open up space for new and much needed Afrocentric epistemes.

In addition, the transformative agenda in the post-school sector in South Africa has largely been driven by an economic imperative (Vally and Motala 2014) aimed primarily at securing the requisite skills required in the labour market. The recent White Paper on Post-School Education and Training (DoHET 2013), despite positing the notion of knowledge creation as an important goal, can be said to provide a narrow skills-driven agenda for the transformation of the post-school sector in South Africa in the next few decades. This is partly because of the relative size of the non-university sector in relation to the smaller university sector. It is also because of the sheer magnitude of challenges relating to quality, wastage, curricula issues, qualifications, alignment to economic needs and human resources deficiencies which tend to muster greater attention of policy makers. But more importantly, the non-university post-school sector is seen as having a mandate which is more directly related to the skills needs of the economy in terms of preparing people for direct employment into its various sectors. There is an extensive critique available on the questions of unemployment, underemployment and casual 
employment, which is beyond the scope of this article (Vally and Motala 2014, for example).

\section{STRUCTURE OF THE POST-SCHOOL SECTOR IN SOUTH AFRICA}

South Africa's post-school sector is 'located at the nexus between the formal education system and the work place' (Nzimande 2012, viii). As such, the sector is seen as a conduit to the world of work and it comprises:

- $\quad$ public universities

- $\quad$ public technical and vocational education and training (TVET) colleges (formerly known as further education and training (FET) colleges);

- $\quad$ public adult learning centres (soon to be absorbed into the new community colleges);

- private post-school institutions (registered private FET colleges and private higher education institutions, also to be renamed TVET colleges);

- $\quad$ the SETAs and the National Skills Fund (NSF);

- $\quad$ regulatory bodies responsible for qualifications and quality assurance in the post-school system such as the Council on Higher Education (CHE) and the South African Qualifications Authority (SAQA).

A common mandate for all these different institutions and entities is to 'ensure that those entering the labour market are qualified and competent to take up employment and income generating opportunities that exist and that will exist as the economy grows and changes in the future' (Nzimande 2012, viii). It is clear that transformation of the post-school sector in South Africa is largely driven by a skills development imperative, in order to meet the needs of an expanding labour market.

The term post-school sector is used widely but variously in different countries. However, it carries certain limiting connotations, two of which are critically important. Firstly, because the term is all-inclusive, it has become a broad church which has several denominations which often lack coherence and articulation, not to mention quality. Combining the business of universities alongside that of FET colleges, private learning providers in the trades, skills, knowledge, service, and IT markets and hoping that this gigantic sector can be beaten into some shape and form is at best a Herculean ambition and at worst an exercise in futility. Secondly, because of its size and diversity, the sector brings together elements that have potentially conflicting and contradictory purposes. For example, universities everywhere are societal institutions for the socialisation of enlightened, responsible, and constructively critical citizens. 
Their major contribution to society is creation, sharing and evaluation of knowledge (Odegaard 1970). As such they play a less direct role in the development of hard labour market skills, such as the training of artisans, administrators, and apprentices, among others. However, universities contribute enormously through the development of transferable and lifelong skills of analysis, criticality, endurance and persistence, engagement with democratic processes, technological, scientific, numeracy and linguistic literacies essential for meaningful contribution in postmodern societies. Such skills are not employment specific but enhance employability of graduates in the world of work in diverse employment sectors. Hard skills tend to be employment specific and planning based on forecasts about, for example, numbers of boilermakers needed in the next 20 years assume that boiler making as an occupation is unlikely to change in terms of its skills requirements and the training that is needed. However, despite these critical comments, the broad church approach in South Africa has more potential for achieving coherence and articulation if the necessary resources and time are utilised effectively towards that goal and if a minimum set of considerations (which we suggest towards the end of this article) are reflected upon as a prelude to the transformative process. Yet, despite this potential, these issues have remained a huge obstacle in the South African post-schooling system. Thus, the structure of the post-schooling sector in South Africa, focused as it is on preparing young people for the world of work, embeds several contradictions and tensions and marginalises other important roles of the sector, especially those related to knowledge production, development, dissemination and evaluation. This article has three specific aims:

1. to explore the challenges faced by the post-school sector in South Africa

2. to critically examine the rationales and challenges associated with a skills-driven agenda for the post-school sector

3. to offer a theoretical framing for guiding the ongoing transformation of the post-school sector in South Africa.

Structurally, the article begins with a critical reflection of the historical antecedents which have nurtured the need for transformation of the post-school sector in South Africa; it then discusses the notion of skills and transformation in the context of HE. The article then examines the affordances and constraints of a skills-led transformation agenda for a developmental state such as South Africa. It ends with a proposition for a framework that may be deployed to drive transformation in South Africa's post-school sector beyond the narrow confines of a skillsdriven agenda. 


\section{A BRIEF HISTORICAL REFLECTION}

Apartheid has had a lasting impact on socioeconomic development in general in South Africa. It can be argued that its lasting legacy has been that it continues to be blamed for everything that goes wrong in contemporary society forcing people to retreat to discourses of the return of apartheid. Apartheid created a differentiated system of education based on warped beliefs of racial superiority and inferiority (Kallaway 2002). Blacks were educated for largely instrumental reasons, i.e. so that they could take their places as loyal servants providing cheap labour for the main sectors of the economy. Education (or more accurately mis-education) was therefore at the heart of apartheid. It was the basis for the social engineering project which cemented white superiority and black inferiority in a society which lived separately and was based on legitimated injustices, racialised privilege, dominance and subjugation. The historical roots for a skills-driven society, based not on principles of human emancipation, but subjugation, can be traced back to the apartheid era and beyond to the colonial era. This current skills agenda, despite no longer being based on the segregationist system of apartheid continues to dominate educational planning and transformation in South Africa today. Vally and Motala (2014) warn us against the danger of reducing educational provisioning to meet narrow economic ends and invite educators, researchers and society at large to broaden the horizon of thinking through greater theoretical introspection and through reflection on the broader social mission of post-school education in the country. This overbearing focus on skills creates a shadow in which other equally or more important agendas experience stunted growth and under which the full potential of a transformed educational sector can become seriously undermined.

\section{TRANSFORMING THE POST-SCHOOL SECTOR IN SOUTH AFRICA}

Following Beets and Louw (2005), Hindle (2003), Motala (1998) and Carrim (2003), among others, we argue that transformation in education is founded on four interrelated assumptions. The first is recognition of the need for change. In the case of South Africa, education had to be transformed from being a tool for cementing privilege of the minority, based on a segregated and unequally resourced system. In South Africa, this recognition meant that first and foremost, education needed a complete ideological change. The second assumption is based on the recognition that the people with whom these changes are to be effected require some new capabilities and that the spaces they occupy need commensurate transformation. The third is that the transformative process is never straightforward as it has to deal with human resistance, blind spots and contradictions. Finally, transformation requires substantial financial investment, 
as no amount of goodwill alone will turn around the status quo. We use these sets of principles in our analysis of the transformative process in South Africa's post-school sector.

O’Donnell and Schmitter $(1986,38)$ wrote about transformation as a series of transitions aimed at changing the status quo and which are characterised by:

... surprises and difficult dilemmas; elements of accident and unpredictability; crucial decisions taken in a hurry; of actors facing insolvable ethical dilemmas and ideological confusions; of dramatic turning points reached and passed without an understanding of their future significance.

Much of this rich description has characterised transformation of the post-school sector in South Africa since 1994. Summarising the key areas of transformation, Badat (2010) writing for the Development Bank of South Africa (DBSA) identified among others, four specific areas of change in HE in South Africa. These are:

1. Ideological transformation. Transforming a previously elitist and segregated system of HE meant that difficult choices had to be made between the maintenance of quality on one hand and mass access to a broader society in the context of limited and finite resources on the other. Government chose the latter in line with the constitutional imperatives of creating a democratic and inclusive society. However, the choice to 'massify' HE has resulted in an acutely underfunded and wasteful HE, where upward of 60 per cent of those who enter university are unable to complete their studies due to failure, dropping out and severe underperformance. For those who make it through, the degree outcomes are such that employers question the quality of the learning and the capability of the graduates to fit and meet the needs of the market. Needless to say, the majority of graduates affected by this are those who were historically disadvantaged. Transformation located at the intersection of equity and access creates tensions that need careful responses - responses that do not perpetuate inequalities and exclusions; or at worst giving rise to new forms of inequality and exclusions.

2. Expanding the post-school sector. The pre-democracy post-school provision was severely restrictive and offered highly constrained opportunities to the black majority. Increasing capacity was thus seen as an important goal, not only for social justice motives but equally, if not more importantly, for purposes of training more people for the expanding economic development that was envisaged. The National Plan for Higher Education (NPHE) for example set a target of 20 per cent expansion and participation rate for the period between 2008 and 2016. The target seems elusively unattainable as between 
2008 and 2010 the average participation rate only increased by between 1 and 5 per cent while being projected to increase by 8 per cent by 2016 (Badat 2010). Recent announcements by government to increase participation in universities face institutional and sectoral challenges of stretched capacity, poor funding, low pass and graduation rates, inadequate resources for teaching, learning and research and most importantly a perceived and real erosion of quality in the sector.

3. Developing a coordinated and differentiated system of HE. Coordination has partly been achieved through the upgrading of former technology colleges into full-fledged universities, the integration of teacher and nurse training into universities and the mergers and incorporation which saw the previous $36 \mathrm{HE}$ institutions reduced to 23 (now 25 with the opening of two new universities). While the issue of a differentiated system is perhaps more contentious, it is generally assumed that, because of the diverse needs of the South African economy, a heterogeneous post-school sector is better than a homogeneous one. As such, for example, we have at least four different types of universities in South Africa, as discussed earlier. The challenge of growing a diverse and differentiated system is that it becomes more complex to draw up an equitable funding and resourcing formula especially in an environment which places some activities such as research at the top of the hierarchy of university purposes. In reality, the more research-focused universities tend to draw better funding than those which are vocational and teaching oriented. Some have argued that the current funding mechanism in HE encourages isomorphism more than it does differentiation (Badat 2010). For example, even the traditional vocationally oriented institutions see and would like to be seen as research intensive, encouraging mission drift and compromising the production of diploma and certificate trained artisans in preference for degree trained students (Nzimande 2012). However, without parity of esteem between vocational and academic qualifications; between research and teaching, it is difficult to see how a differentiated system will be equitable at the same time.

4. Transforming the intellectual spaces. The legacies of intellectual colonisation and racialisation (Bentley, Habib and Morrow 2006) have been identified as a serious threat not only to academic freedom but also to the post-94 project of democratising all the institutions serving the South African society. The transformation agenda in the university sector has several thrusts, key of which are to:

- increase black faculty engagement in programmes and departments

- increase the proportion of indigenous faculty across all programmes

- increase the participation of formerly disadvantaged learners in programmes of 
learning, especially in previously white dominated Science, Technology Engineering and Mathematics (STEM) disciplines

- provide a variety of support systems to overcome deficits associated with nontraditional university participants.

While much has been achieved in transforming the intellectual spaces in South African universities, more still remains to be done. For example, some have argued that changing the colour of university participation and representation without transforming the epistemological and ontological content of what students learn and what lecturers teach does little to transform the intellectual terrain of our institutions. Badat $(2010,18)$ for example has written: '.. the space for the flowering of other epistemologies, ontologies, issues and questions other than those that have dominated, perhaps even suffocated intellectual thought and writing ... have not changed much in our universities despite the transformation'.

But while all this has been happening (or indeed not happening), the most recent White Paper for HE repeatedly mentions change and transformation, even though it remains locked in the discourse of a skills-led transformation, which this article now addresses.

\section{MEANING AND RATIONALE OF A SKILLS FOCUS IN THE POST-SCHOOL SECTOR IN SOUTH AFRICA}

The term skills has several dimensions, some relatively conventional while others require a little more intellectual stretch. In education, skills can be classed in three categories. Employment skills are related to requirements for specific jobs in the labour market. For example, hairdressers need skills related to handling and using electrical equipment; relating with clients or customers; the ability to communicate; and listening skills, among others. To secure employment in this trade, one needs to have work experience and training specifically conducted in a hairdressing environment. Because educational institutions do not always have the capacity and resources to offer such experience on campus, they work alongside employers who provide work experience for learners.

The second category of skills is often referred to as generic work- or employment-related skills. These tend to include literacy, numeracy, computer and information technology competences, which are assumed to translate into the general requirements and capabilities across many work situations and environments.

The third category of skills is what may be termed employability skills. These tend to emphasise social employability skills, work ethics, values, relationships, personality, habits and 
other behavioural aspects which are valued by employers. Hind and Moss (2005) have suggested that modern emerging economies tend to emphasise learning and study skills, body language skills, and numeracy skills, working with, and leading other people, problem solving, decision making, critical thinking, information gathering, consultancy and undertaking extended projects. Rather unhelpfully, the policy proposals, despite being focused in a skills discourse, make no attempt to explicate the notion of skills and largely leave the idea undefined.

Sen and Nussbaum (2003) admonish us though against the temptation to provide a list of skills with specific definitions as these can never usefully be used as a basis for constructing broad policy about human development. They argue that lists and specifications work differently in different circumstances and need never be prescribed for all purposes. Instead they argue for the use of human capabilities as a basis for economic planning.

Despite this, three key rationales for a skills-led reform are often advanced in the literature: skills development; enhancing throughput and ameliorating unemployment. The first is related to ameliorating skills shortage in critical areas of the economy. In relative terms, South Africa is arguably the most developed nation on the African continent. However, in absolute terms, South Africa is a developing country with all the attendant challenges. The country has rich mineral resources and agricultural potential. Often described as a two nation state (Mbeki 1998), South Africa has two parallel economies. The first is a modern economy intricately integrated with the global processes and producing the bulk of the nation's wealth. The second is an underdeveloped and marginalised economy which serves the majority of the population in rural and urban townships and which contributes minimally to the nation's GDP (see Fleisch 2008 for an extended discussion of the dual economy thesis).

Supporting this dual economy thesis, despite the official demise of apartheid, South Africa effectively has two parallel systems of education. One is a well-resourced elite system that produces almost the entire cohort of university entrants and graduates (Fleisch 2008). The second system comprises the majority of poor marginalised rural and township pupils learning in under-resourced schools with inadequately trained teachers. Fleisch aptly captured the dual system thesis when he wrote in reference to primary education in South Africa:

In seven years of schooling, children in the second system do learn, but acquire a much more restricted set of knowledge and skills than children in the first system. They read, but mostly at very limited functional level; they write, but not with fluency and confidence; they can perform basic numeric operations, but use inappropriately concrete techniques that limit application (Fleisch 2008, 2).

Five years of secondary schooling leads pupils to the Matric examination which if successfully 
achieved enables pupils to enter university. Only about 10 per cent of pupils achieve this while 90 per cent exit the school system with poor qualifications. Quality of throughput from the secondary schools also reflects the dual nature of the school system with those coming from the first sector recording Matric success while those from the second sector underachieving and generally not going to university.

Generally South African universities consider the throughput from schools as being underprepared for university work (Jansen 2004) and that this leads to all sorts of wastage in the university sector, characterised by increasing numbers of dropouts and stop outs, repeaters and failures and poor quality degree outcomes. In addition, university participation rates based on student socioeconomic background factors confirm the dual parallel thesis in South Africa. Although inconclusive, research also seems to suggest that the quality of degrees obtained across socioeconomic background factors favours graduands from the so- called first economy. In their research on the impact of the recession on educational achievement in South Africa, Taylor and Yuk $(2009,75)$ conclude that: 'The impact of SES on educational achievement is particularly severe in South Africa by international standards' and it can be added that it serves largely to reproduce the inequalities that have been created and entrenched in the society (see Bourdieu 1997; Maggio 1982; Abdi 2002).

Universities perhaps need to rethink the nature and purpose of the first year of the undergraduate programme. Students coming to university for the first time in South Africa have one year less of university preparation in comparison to others in the region and other parts of the world while they are still in school. This represents a significant gap in their readiness for undertaking university work. Rather than providing university-level courses, it may be prudent for universities to consider the first year undergraduate experience as largely preparation for university. There is evidence elsewhere that when university preparation is undertaken at university, the gains to students are significantly higher than when this preparation is undertaken in schools. For example, many American universities now have a first year university preparation programme and most of these programmes have yielded almost 100 per cent progression and success among previously underprepared student groups who hitherto experienced significant barriers in terms of success rates, progression and dropping out of programmes. Zambia also has a similar approach and has one of the most efficient university programmes on the African continent. Students undertake 'A' level work in the first year of university.

This leads to a second rationale for a skills-driven restructuring of post-schooling sectors which is about improving throughput from the schooling sector. This can be achieved in many 
ways but chiefly by producing more qualified teachers and strengthening teacher quality in university-based training programmes. This is based on substantial evidence which suggests that good teachers drive up standards and outcomes in education (Teddlie and Reynolds 2000; Mortimore et al. 2000).

Unfortunately, a labour market driven restructuring programme tends to focus on meeting the quantitative demands more than it does on the knowledge and research aspects. Consequently, institutions become preoccupied with admitting more and more students as long as government is willing to offer needed financial support. This usually compromises the research role of universities, reducing them to follow a technicist skills-based approach while abandoning the knowledge and research purpose (see for example Mohamedbhai 2008).

A third and arguably more important rationale is related to the idea of ameliorating unemployment levels in the country. Currently there are approximately 3 to 5 million youths between the ages of 18 and 30 not in education, employment or training (NEETs) and general levels of unemployment in the country are estimated as approaching or arguably exceeding the 30 per cent level (Index Mundi 2015). The argument behind the skills rationale is that people become unemployed because they do not have the needed skills relevant in the employment market. This is only partly true and perhaps accounts for a relatively small percentage of unemployment in any country. A larger percentage of unemployment exists due to the inherent problems in capitalism, as Klees (in Vally and Motala 2014, ix) reminds us, without creative job creation and an expanding, not shrinking, economy unemployment levels are likely to increase and the skills drive can only have a limited impact on ameliorating the phenomenon with all its attendant social, health, and political consequences.

\section{CHALLENGES, FAULT LINES AND STICKY ISSUES IN THE SOUTH AFRICAN POST-SCHOOLING SECTOR}

Sectoral systems are designed to deliver services efficiently and effectively. They are also expected to provide equal opportunities for access, success and attainment of outcomes. On all these criteria, the South African post-school sector experiences significant limitations.

Efficient sectors achieve their missions with the minimum resources, without wastage and within timescales. Across all providers, including universities, there is an alarming rate of failure, poor progression and high dropout rates. For example, between 2001 and 2004 the average success rate for all full time students in South African universities was 76 per cent, with African and coloured students scoring lowest at 67 and 69 per cent respectively (Letseka and Maile 2008). Factors contributing to this low rate of success in degree programmes include 
the legacy of apartheid policies (Fiske and Ladd 2004); the multifarious impact of poverty and disadvantage (Fleisch 2008; Sayed and Motala 2009) and structural socioeconomic factors including resource deficiencies and inadequate cultural capital.

The dropout rate has also been quite significant in South African universities. In 2004, the government calculated that it was wasting about R5 billion annually in lost revenue due to dropout phenomena across all universities. Letseka and Maile $(2008,5)$ observed:

In 2005 the Department of Education reported that of the 120000 students who enrolled in higher education in 2000, 36000 (30\%) dropped out in their first year of study. A further 24000 (20\%) dropped out during their second and third years. Of the remaining 60000 , 22\% graduated within the specified three years duration for a generic Bachelor's degree.

Socioeconomic factors were found to have the biggest impact on this phenomenon in South African universities. For example, Black students from poor families earning less than R1 500 a month, most of whom had to work as well as study, comprised nearly 78 per cent of all dropouts across the universities (Macfarlane 2006).

Access and participation data also provides shocking statistics in South African postschool sectors, especially in universities. It may be fair to say much has been achieved since 1994; however, a lot still remains to be done to eradicate inequalities from the system. For example, while black participation rates have gone up by about 40 per cent (from $20 \%$ to 60\%) since 1994, almost 60 per cent of all blacks who finish school are unable to access university chiefly for reasons associated with poor performance (Cross and Carpentier 2009). Gender participation data also reveals wide disparities. Female participation in the science, mathematics and engineering studies is way below threshold levels in relation to comparator countries. The system also remains characterised by racism. In 2008, a committee tasked with investigating the Reitz residence scandal where a group of white students abused black workers concluded that:

... there is a disjunction between policy development and implementation and that discrimination, in particular with regard to racism and sexism, is pervasive in our institutions (Higher Education Monitor 2009, 7)

The sector, especially the FET colleges, is on record as providing extremely poor quality teaching. A key factor in this is the lack of adequately qualified staff to teach the college curriculum. The Green paper identifies resource inequalities; inadequate infrastructure; resources; weak student financial aid and support; poor institutional governance administration and intra-institutional relations as the key obstacles to transformation.

Even though it operates under the same umbrella, the post-school system in South Africa 
is described as fragmented, incoherent and poorly articulated. It is currently difficult for crosssector transfer of learning and articulation with the labour market, both in terms of matching supply to demand and in terms of creating links that deliver appropriate and quality work experience for students.

\section{TOWARDS A RECONCEPTUALISATION OF TRANSFORMATION}

South Africa is entering a new phase of transformation of its post-schooling sector. A key purpose of this article was to explore some of the tensions associated with transformation. A key thrust of this article is that a skills-led reform provides an inadequate and inappropriate basis for the reform the sector needs and deserves. Throughout our discussion the article reiterates the inadequacy or inappropriateness of underpinning skills as the only basis for reforming education and the post-school sector in South Africa.

Conceptualising sectoral reform on the basis of skills has been argued to be inappropriate and inadequate for contemporary South Africa for a number of reasons. These include:

- That South Africa, though significantly still based in an industrial mode of production, has a significant and exponentially expanding post-industrial economy driven more by knowledge and information than by skills.

- That, with increasing globalisation, knowledge and information is predicted to be the new bases of labour in the future. Transformation agendas which focus on skills and ignore this new reality are likely to be planning for a future which will not exist any longer.

- That a skills-driven reform nurtures a qualifications-driven schooling system in which the value of learning is supplanted by the value of qualification acquisition (see Dore 1976; Freeman 1976; Milner 1972). Although these texts are somewhat dated, contemporary researchers appear to be still coming up with similar conclusions (see for example Vally and Motala 2014; Badat 2010; Bloch, Chisolm, Fleisch and Mabizela 2008; Fiske and Ladd 2004).

- That practice in schools suggests that skills curricula are usually reserved for the academically less able. This is likely to reproduce and perpetuate societal inequalities maintaining the social distribution of careers and occupations along lines of socioeconomic background factors, similar to the intentions of apartheid education (see for example Lopez-Mayan 2010; Willis and Rosen 1978; Arcidiacono 2004).

- $\quad$ That it is a myth that skills development reduces unemployment (see for example Vally and Motala 2014). 
- $\quad$ Future earnings in skills-related careers are likely to be relatively less compared to those in knowledge- and information-based careers. This tends to drive student choice more towards subject study in areas with less practical orientation (See for example Foskett, Dyke and Maringe 2004).

- A skills-led reform has the potential to reduce post-schooling institutions, and universities in particular, to operate along a technicist agenda which responds to government's requirements for producing more and more technical graduates. In periods of austerity, universities may have little choice as they follow funding streams which favour the technicist imperative. This often relegates the knowledge responsibilities of universities to the second tier of priorities (Vally and Motala 2014).

In addition, we argue that the notion of transformation itself seems to be based largely on the identification and spelling out of good intentions. As indicated above, the many good intentions including the need to transform the ideological, structural, spatial and intellectual spaces suggest that recognition of the impetus for change has been given enough attention in the conceptualisation of the transformative processes. However, the record of transformation suggests that much of what was intended has not quite materialised. For example, while the envisaged ideological transformation through massification and democratisation of access has resulted in significant increases in participation rates, inadequate funding and weak internal support systems have created new forms of inequality and inequity which manifest in terms of differentiated student performance based primarily of race and various forms of educational wastage. The levers of finance and support which would have helped propel the intended ideological transformation have slowed down the transformative process creating in the process new sources of inequalities.

The same results are seen in the context of the ambition to build a coordinated and diverse system. The complexities associated with this and the huge inertia of the academy in respect of the prioritisation of research over teaching; the eminence of the academic curriculum over the vocational have combined to produce a system with significant mission drift towards the prestigious research especially amongst the former traditional vocational institutions. The barriers to transformation in this regard have not been given much consideration and are now driving new forms of unintended and possibly contradictory transformation.

The approach to transformation can be argued to have been largely a-theoretical, based on good intuition and instinct. Some have argued that the economic imperative of transformation has been the major force behind transformation so far to which a skills-driven agenda has been 
used as a major tool. In the process, the social project of higher education including, especially for universities, the knowledge production role, do not seem to feature prominently or at least are overshadowed by the discourses of jobs and job creation. Conceptualising transformation needs to go beyond the narrow imperatives of the economy (see Vally and Motala 2014).

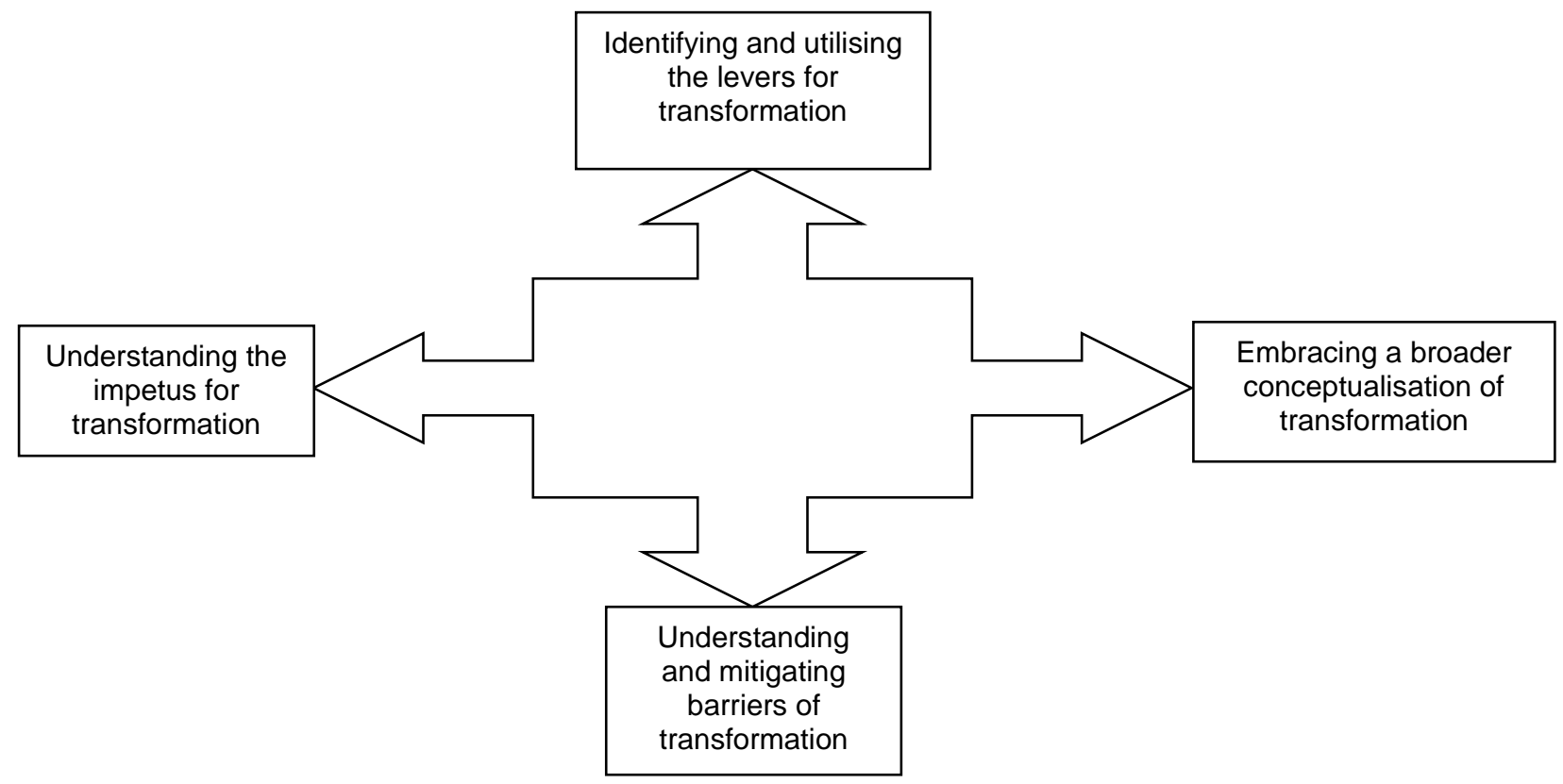

Figure 1: A mapping/force field of frameworks of transformation

In conclusion, the article suggests that transformation of post-school sectoral education systems needs to confront four broad issues which are depicted in Figure 1. These four issues, which we call frameworks of transformation, precede and indeed inform policy implementation which itself requires a whole set of different considerations beyond the scope of this article. These frameworks of transformation include:

- $\quad$ an understanding of the impetus for change;

- $\quad$ recognising the variety of conceptualisations of transformation;

- $\quad$ capitalising on the levers of change and

- $\quad$ a deep appreciation of the barriers of transformation.

\section{UNDERSTANDING THE IMPETUS FOR TRANSFORMATION}

The impetus for transformation is created by perturbations and sources of disequilibrium in the system. For the South African post-school system, such perturbations and sources of disequilibrium include systemic inequalities and inequities; systemic racism; low quality of educational/training experience; systemic wastage; poor programme articulation; inadequate 
capacity and quality (see for example Badat 2010). While policy makers have been good at identifying such sources of disequilibrium in the system, they have not been as good in determining the nature and extent of these issues as the need for change has been and continues to be glaringly evident. Post-school institutions and the government have a role to play in human development and developing communities. They need to ensure that post-schooling is responsive to local needs and works in favour of communities. This may mean that some of the research and the teaching in such institutions are in touch with the daily issues facing different communities and advances knowledge about these needs. Beyond skills, knowledge has to take on a new impetus for developing communities, rather than just industrialisation and economic growth. Unfortunately, the next three pillars discussed below have not been fully conceptualised nor have they been fully integrated in the transformation effort at the level of policy and practice. An insecure understanding of the impetus for change could easily lead to change for its own sake or to poor diagnosis or to the perpetuation of the status quo as seems to be happening in the post school sector.

\section{IDENTIFYING AND UTILISING THE LEVERS OF TRANSFORMATION}

Levers are enablers; those structures, processes, systems, and even cultures that aid the transformative process without which the whole process would be difficult or even impossible. Such levers might include for example suitably qualified and motivated human resource; adequate financial and other material resource; appropriate leadership and management resource; sufficient goodwill and support for the transformation; processes for identifying and managing sources of ongoing perturbations, discontinuities and disequilibrium. These levers have not been sufficiently used, nor indeed conceptualised, and one of the levers of transformation, i.e. adequate funding, has been seriously neglected. In South Africa, despite the skills agenda, the employment sector is not producing many jobs. On the contrary the rate of unemployment has been increasing in the past five years and is currently at its highest at about 25 per cent (Vally and Motala 2014). A good level for promoting a skills agenda in the post school sector would be a rising rather than dwindling rate of employment.

\section{EMBRACING A BROADER CONCEPTUALISATION OF TRANSFORMATION}

Transforming educational systems has largely been an a-theoretical process which is based on the availability of resources and considered through raw gut instinct, political imperative and rational systemic planning. The new phase of transformation we are entering appears once again to be dominated by a narrow skills agenda. The resource of theory has a significant role to play 
in both the conceptualisation and analysis of the impact of transformation. Understanding both the physiology and anatomy of transformation, informed by existing theories and acknowledging that education is not just about skills training for the labour market is an important ingredient in successful educational change. Our transformation in South Africa seems heavily dependent on skills training and the labour market imperatives, without due regard for human development and of narrowing the inequality gap through transformation.

If we are to move beyond a narrow skills approach then looking to theories of adult education, and adult learning which have always had adult learners as the centre of attention may take us forward. Such paradigmatic shifts will turn attention to the personal development and well-being of adult learners, their needs and desires for professional development and their agency in social change and transformation. In addition, such a theoretical focus ensures that the post-school sector addresses the needs of communities rather than just the market.

Critical adult education is well placed to provide the theoretical basis for transforming the post-school sector. It focuses on the learning of individuals and groups and draws on the rich traditions of student-centeredness for its pedagogical underpinning. It questions dominant forms of knowledge and it questions the '... status of the definitive, the certain and the proven' (Usher 1992, 210). Such a theoretical approach counters a narrow skills approach because it serves to reverse practices, attitudes and beliefs that serve to limit the potential and status of people in society. Such a framing will propel a passion for the post-school sector that is just and fair - 'one that ... links struggle to a new set of human possibilities' (Giroux 1983, 242).

In South Africa, transforming the post-school sector informed by critical adult education theory will ensure that such reform takes sides with social movements to influence equity and justice in a democratic society. Such a framing connects with the material realities of ordinary people's lives (Apple 1993). It is '... an integral part of the struggle for democracy and social justice' (Martin 1999, 181) on the one hand, and about giving learners a good shot at education.

Such a framing recognises the educative value of experience obtained from everyday life, work and community; that such experience is made of knowledge and skills, but also of traits such as focus, self-discipline and self-knowledge. These attributes form the basis for further growth and development. Transformation along these lines will espouse personal and collective empowerment and social change for disadvantaged groups. This is particularly valuable in South Africa where a reformed post-school sector is strongly linked to imperatives of social justice in education.

\section{UNDERSTANDING AND MITIGATING BARRIERS TO TRANSFORMATION}


Systems are naturally resistant to change as maintaining a status quo often offers a path of least resistance in their development processes. Such resistance to change occurs at various levels and in varying degrees of intensity, including, amongst others (Hargreaves 2005) systemic unpreparedness for change; a 'we have always done things this way' culture; lack of resources to support change; habit of piecemeal reform; divided loyalties which prevail above organisational or systemic synergies. Developing a systemic intelligence which identifies, interrogates and manages barriers is an important pillar in the force field of transformation. In the South African terrain, these barriers have thrived and continue to create detours and dead ends and in the process compromised the achievement of the good intentions that lie beyond.

Going back to the beginning, while transformation of the post-school sector in South Africa is both urgent and necessary, it is unlikely to be fully served by a dominant skills-led agenda. Post-school education and training reform cannot just be about training adults to enter the labour market. A broader definition of skills which relate to and include facets of abilities and capabilities must figure in such definitions. Education institutions have a crucial role to play here, ensuring that they do not inadvertently collude with policy that marginalises the already marginalised. Instead, they should theorise post-school education reform in a way that stays true to a social justice agenda, which is deeply rooted in the needs of communities and responsive to human development instead of human exploitation rooted in the market. Moreover, the challenges we experience today, in the form of persisting inequities in access, participation performance and persistence, suggest that good intentions on their own do not transform our education systems. Systematic analysis, a part of which this article offers in the form of the four pillar force field of transformation, could help in reimagining proposals for reform, which could stand a more realistic chance of success. We offer this model as a tentative tool to inform the ongoing debates on transformation in the post-school sector in South Africa.

\section{REFERENCES}

Arcidiacono, P. 2004. Ability sorting and the returns to college major. Journal of Econometrics 121: 343-375.

Abdi, A. A. 2002. Culture, education and development in South Africa, historical and contemporary perspectives. Johannesburg: Greenwood Publishing.

Apple, M. W. 1993. Official knowledge: Democratic education in a conservative age. New York: Routledge.

Badat, S. 2010. 'The challenges of transformation in higher education in South Africa.' Paper commissioned for the Development Bank in Southern Africa (DBSA), RSA.

Beets, P. and Van T. Louw. 2005. Education transformation, assessment and Ubuntu in South Africa. In African philosophy of education, reconstructions and deconstructions, ed. Y. Waghid et al. Stellenbosch: Department of Educational Policy Studies, University of Stellenbosch. 
Bentley, K., A. Habib and S. Morrow. 2006. Academic freedom, institutional autonomy, and the corporatised university in contemporary South Africa. Pretoria: Council on Higher Education.

Bloch, G., L. Chisholm, B. Fleisch and M. Mabizela. eds. 2008. Investment choices for South African education. Johannesburg: Wits University Press.

Bourdieu, P. 1997. Reproduction in education, society and culture. Beverley Hills, California: SAGE.

Carrim, N. 2003. Teacher identity, tensions between roles.” In Changing patterns of teacher education in South Africa, ed. K. Lewin, W. Samuels and Y. Sayed. Cape Town: Heinemann.

Cross, M. and C. Carpentier. 2009. New students in South African higher education, institutional culture, student performance and the challenges of democratisation. Perspectives in Education 27(1): 618.

DoHET see Department of Higher Education and Training.

Department of Higher Education and Training. 2013. White Paper for post school education and training, building and expanded, effective, and integrated post schooling system. Republic of South Africa.

Dore, R. 1976. The diploma disease, qualifications and development. Berkeley: University of California Press.

Fiske, E. B. and H. F. Ladd. 2004. Elusive equity: Education reform in post-apartheid South Africa. Brookings Institution Press: Washington, D.C.

Fleisch, B. 2008. Primary education in crisis: Why South African school children underachieve in reading and mathematics. Cape Town: Juta.

Foskett, N., M. Dyke and F. Maringe. 2004. The influence of the school in the decision to participate in learning post-16. Southampton: DfES Publications.

Freeman, R. 1976. The over educated American. New York: Academic Press.

Fuschs, C. 2008. Internet society, social theory in the information age. New York, Routledge.

Giroux, H. 1983. Theory and resistance in education. Massachusetts: Bergin and Garvey.

Hargreaves, A. 2002. 'Teaching in the knowledge society.' Vision 2020, Second International Conference, 13-26 October and 24 November to 7 December 2002.

Hargreaves, A. 2005. ed. Extending educational change: International handbook of educational change. New York: Springer.

Higher Education Monitor. 2009. Postgraduate studies in South Africa, a statistical analysis. No. 8: 7. Council for Higher Education, Cape Town: DoHET.

Hind, D. and S. Moss. 2005. Employability skills. Sunderland: Business Education Publishers Limited.

Hindle, D. 2003. A prospective teacher education agenda. In Changing patterns of teacher education in South Africa, ed. K. Lewin, W. Samuels and Y. Sayed. Cape Town: Heinemann.

Index Mundi. 2015. Unemployment rates. http://www.indexmundi.com/south_africa/unemployment_ rate.html (accessed 20 June 2014).

Jansen, J. 2004. Changes and continuities in South Africa's higher education system, 1994 to 2004. In Changing class: Education and social change in post-apartheid South Africa, ed. L. Chisholm, 293-314. Pretoria: HSRC Press.

Kallaway, P., ed. 2002. The history of education under apartheid, 1948-1994. The doors of learning and culture shall be opened. New York: Peter Lang.

Klees, S. J. 2014. Foreword to Education, Economy and Society. In Education Economy and Society, ed. S. Vally and E. Motala. University of South Africa: UNISA Press.

Letseka, M. and S. Maile. 2008. High university drop-out rates: A threat to South Africa's future. HSRC Policy Brief. http://www.hsrc.ac.za/Document-2717.phtml (accessed 10 May 2012). 
Lopez-Mayan, C. 2010. Demand for post-compulsory Education: The choice between academic and vocational tracks. http://www.iza.org/conference_files/SUMS2010/lopez-mayan_c6109.pdf (accessed 1 April 2015).

Macfarlane, D. 2006. Shock varsity dropout stats. Mail \& Guardian 22-28 September.

Maggio, P. 1982. Cultural capital and school success. The impact of status, culture and participation on the grades of US High school students. American Sociological Review 47(2): 189-201.

Martin, I. 1999. Reconstituting the Agora: Towards an alternative politics of lifelong learning. http://www.adulterc.org/Proceedings/2000/martini-final.PDF (accessed 20 June 2014).

Mbeki, T. 1998. South Africa: Two nations. Statement of Deputy President Thabo Mbeki at the opening of the debate on reconciliation and nation-building, National Assembly, 29 May. Quoted in The Life and Times of Thabo Mbeki, 1999. A. Adrian Hadland and J. Rantao, 188. Cape Town: Zebra Press.

Mbembe, A. 2001. On the post-colony, studies on the history of society and culture. California: University of California Press.

Milner, M. 1972. The illusion of equality, the effects of education on opportunity, inequality and social conflict. San Francisco: Jossey Bass.

Mohamedbhai, G. 2008. The effects of massification on Higher education in Africa. http://www2.aau.org/wghe/scm/meetings/mai08/adea/study_massification.pdf (accessed 13 May 2012).

Mortimore, P., S. Gopinathan, E. Leo, K. Myers, L. Sharpe, L. Stoll and J. Mortimore. 2000. The culture of change: Case studies of improving schools in Singapore and London. London: Institute of Education, Bedford Way Papers.

Motala, S. 1998. Quarterly Review of education and training in South Africa 5(5).

Mudimbe, V. Y. 2013. On African fault lines: Meditations on alterity politics. University of KwaZuluNatal Press.

Nzimande, B. 2012. Minister's Preface. Green paper for post-school education and training. Cape Town: DoHET.

Odegaard, C. E. 1970. A description of the role of the university in modern society. California Medicine, New York: Josiah Macy Jr. Foundation.

O’Donnell, G. and P. C. Schmitter. 1986. Transitions from authoritarian rule, tentative conclusions about uncertain democracies. Baltimore: John Hopkins University Press.

OECD. 1996a. Employment and growth in the knowledge-based economy. Paris.

OECD. 1996b. Technology, productivity and job creation. Paris.

Reynolds, D., C. Teddlie, D. Hopkins and S. Stringfield. 2000. Linking school effectiveness and school improvement. In The international handbook of school effectiveness research, ed. C. Teddlie and C. Reynolds, 206-231. London: Falmer Press.

Samuel, M. and W. Morrow. 2004. Continuing teacher professional development. Draft Discussion document, National Framework on Teacher Education. Paper presented at the CEPD Conference on The role of Education in a decade of democracy, Johannesburg.

Sayed, Y. and S. Motala. 2009. Fee free schools - Free and fair? CREATE, South Africa Policy Brief. The Education Policy Unit at the University of the Witwatersrand, South Africa.

Sen, A. and M. Nussbaum. 2003. Capabilities as fundamental entitlements: Sen and social justice. Feminist Economics 9(2-3): 33-59.

Taylor, S. and D. Yuk. 2009. Socioeconomic status and educational achievement: Does education provide a stepping stone out of poverty in South Africa. www.ijr.org.za/publications/ pdfs/IJR_TA_chapter3.pdf (accessed 9 May 2012).

Teddlie, C. and D. Reynolds, ed. 2000. The international handbook of school effectiveness research. 
London: Falmer Press.

Toffler, A. 1980. The third wave. New York: Bantam Books.

Usher, R. 1992. Experience in adult education: A post-modern critique. Journal of Philosophy of Education 26(2): 201-214.

Vally, S. and E. Motala. 2014. Education, economy and society. Pretoria: UNISA Press.

Willis, R. J. and S. Rosen. 1979. Education and self-selection. Journal of Political Economy 87: S7S36.

Zeleza, P. T. 2005. Transnational education and African universities. Journal of Higher Education in Africa / Revue de l'enseignement supérieur en Afrique 3(1): 1-28. 